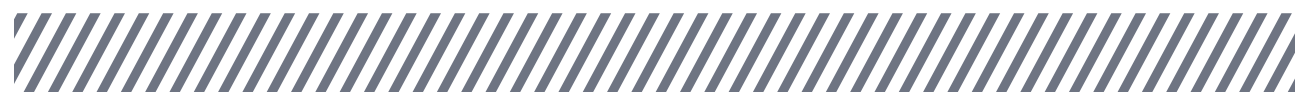

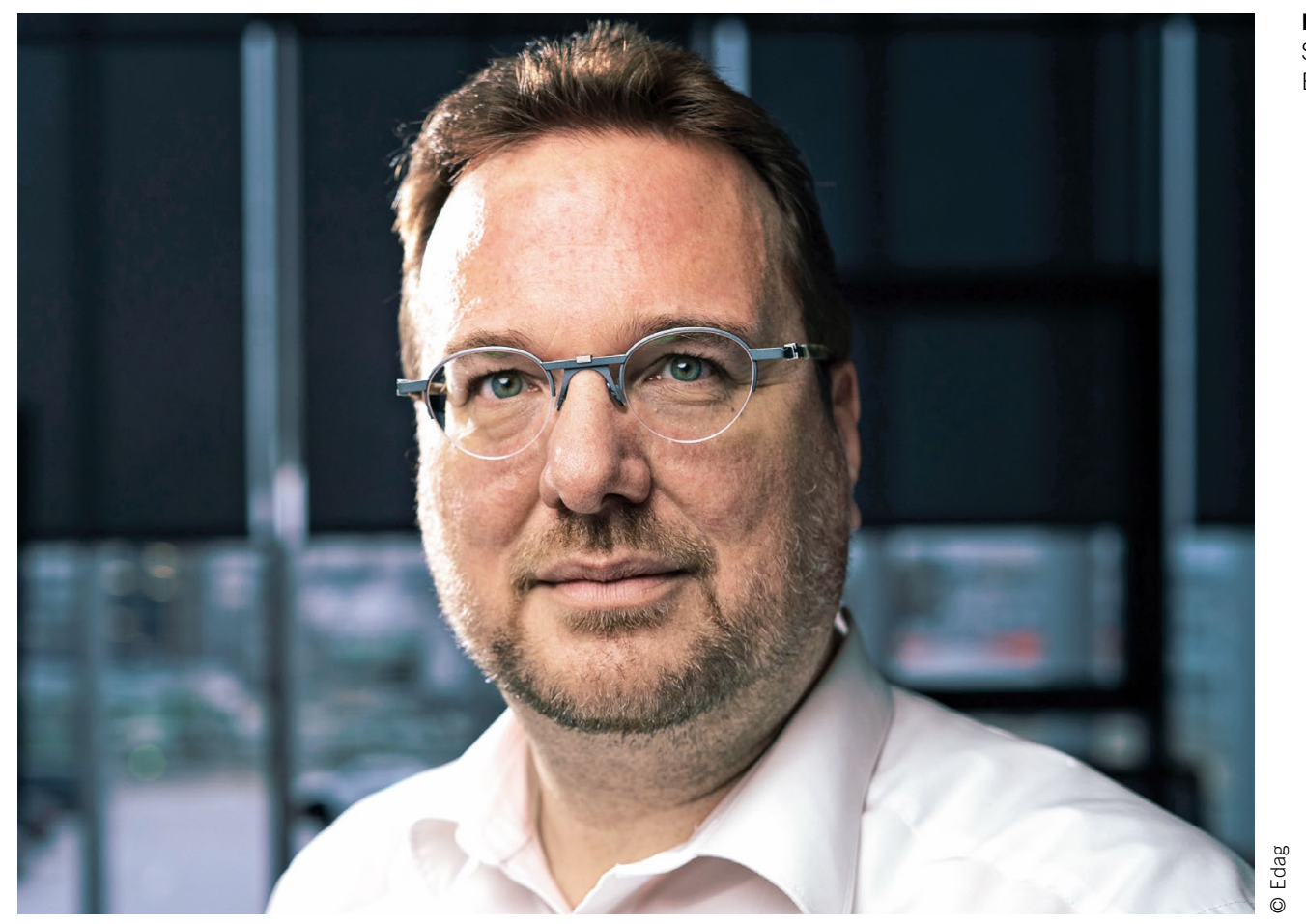

Dr. Jochen Hagel

Senior Vice President

Electrics/Electronics, Edag

\section{Treiber der Mobilitätsrevolution}

Die Automobilindustrie ändert sich aktuell fundamental. Grundlegend neue Technologien werden ins Fahrzeug integriert und gleichzeitig etabliert sich eine neue Rollenverteilung zwischen Herstellern und Zulieferern. Auffällig ist aber insbesondere, wie stark neue Motivationsfaktoren wie Nachhaltigkeit und digitale Lebensräume die Veränderung der künftigen Mobilität beeinflussen. Dabei ist Nachhaltigkeit weit mehr als nur die Ablösung des Verbrennungsmotors. Im Fokus stehen neue Mobilitätskonzepte, zum Beispiel zur Förderung der Lebensqualität in den Innenstädten oder zur Reduktion des Gesamtenergieverbrauchs durch die Kombination von spezialisierten, für den jeweiligen Einsatzzweck optimierten Transportmittel. Dazu sind neue Fahrzeugkonzepte erforderlich, insbesondere für den innerstädtischen Transport von Personen und Waren.

Ein Fahrzeug ist heute längst nicht mehr vorrangig ein Fortbewegungsmittel, es ist die Erweiterung unseres immer stärker digital geprägten Lebensraums. Dieser soll durch die genutzten verschiedenen Mobilitätsplattformen möglichst bruchlos miteinander verbunden werden. Dazu ist es erforderlich, eine

Vielzahl von IT- und Kommunikationstechnologien in das Automotive Software Ökosystem zu integrieren. Individualisierung spielt dabei eine wichtige Rolle - und das möglichst unabhängig vom gewählten Fahrzeug. Die Einbindung von Android und iOS stellt dabei nur eine der Herausforderungen dar.
Software ist vermehrt die Schlüsselkompetenz, um die Marktposition der Fahrzeughersteller zu sichern. Dabei geht es nicht nur um die Weiterentwicklung von Fahrzeug-Features, sondern vielmehr darum, Innovationen in hoher Qualität in ein Serienfahrzeug zu bringen. Gerade hierbei können Engineering Dienstleister einen wichtigen Beitrag leisten, um Entwicklungsfreiräume für Innovationen bei etablierten Fahrzeugherstellern zu schaffen und innovative neue Hersteller im Serienentwicklungsprozess weiter zu befähigen.

Die neue Mobilität ist nur im Verbund vieler Mitspieler und Technologien realisierbar. Dies kann die gemeinsame Erfassung und Nutzung von Daten sein, die Anbindung an Infrastrukturbetreiber oder die Einbindung von hoch spezialisiertem Know-how eines Start-ups in Serienentwicklungsprojekte. Mit ihrer langjährigen Automotive-Erfahrung und dem Fokus auf methodische Exzellenz können gerade an solchen Schnittstellen Entwicklungsdienstleister einen wichtigen Beitrag leisten. Sie müssen in Zukunft vermehrt eigene Methoden und Werkzeugkästen bereitstellen, um die neuen Technologien effizient und im Automotive-Standard zu operationalisieren. Dabei sind sie gefordert, künftig vermehrt auch in Innovationsprojekte $\mathrm{zu}$ investieren, um so eigene Entwicklungswerkzeuge oder Funktions- und Testbibliotheken bereit zu stellen, die dann in Serienprojekte einfließen können. 